Copyright (C 2015 IEEE. Personal use of this material is permitted. Permission from IEEE must be obtained for all other uses, in any current or future media, including reprinting/republishing this material for advertising or promotional purposes, creating new collective works, for resale or redistribution to servers or lists, or reuse of any copyrighted component of this work in other works. 


\title{
Motivating Power System Protection Course Students by Practical and Computer-Based Activities
}

\author{
Farhad Shahnia, Senior Member, IEEE, Moayed Moghbel, Student Member, IEEE, \\ and Hadi Hosseinian Yengejeh, Student Member IEEE
}

\begin{abstract}
This paper presents several methods for motivating students taking a power system protection (PSP) course. The paper reviews the laboratory activities developed for the PSP course at Curtin University, Australia; these methods are applicable and can be used for PSP course instruction at any institution. These activities were developed to improve the learning experience of the electrical engineering undergraduate and postgraduate students enrolled in this course. Initially, the PSP course at Curtin University consisted of lectures and tutorials accompanied by two sessions of software-based simulations and one session of laboratory demonstration. To motivate the students, several computer-based simulations and practical laboratory experiments were developed. PSCAD and ETAP power system analysis software tools are introduced and used to demonstrate the performance and coordination of different protection relays from steady-state and dynamic points of view. Also, a practical setup composed of a LabVolt power system simulator and industrial relays is used to carry out several practical experiments. The experiments help students observe the performance of protection systems for transformers and induction motors during faults and abnormal operating conditions. Finally, the concept of relay testing and commissioning is introduced by relay stand-alone experiments using a secondary injection relay test set. The results of these activities were evaluated according to the students' satisfaction, comments, total scores and interest in PSP.
\end{abstract}

Index Terms-Education, power system protection, student motivation, student satisfaction

\section{INTRODUCTION}

Protective relaying plays a vital role in detecting a fault or disturbance in power systems, and in isolating local parts of the network in a timely fashion [1]. Proper operation of the protective relays avoids damage to the utility equipment, reduces electricity interruptions to wider areas and more customers, and also minimizes hazards to utility personnel [2]. Because of the importance of protective relaying, the theories of protecting a power system are usually introduced to electrical engineering students within power system analysis or power system protection (PSP) courses.

Individual PSP courses are offered for undergraduate or postgraduate students in a few universities around the world, with the main prerequisite being a knowledge of power system analysis (mainly load flow and short-circuit fault calculations). The course's main objective is to introduce various protection schemes (e.g., overcurrent, directional, distance, differential, thermal, earth-fault, and so on), various relay types (i.e., electromechanical, numerical and microprocessorbased), relay setting calculations, and coordination of power system relays. The IEEE Power System Relaying Committee
(PSRC) recommends that PSP courses should consist of standard lectures, laboratory sessions, software sessions and assignments [3]. Among all these learning activities, this paper focuses on the laboratory and software sessions.

Laboratory exercises play a vital role in improving the learning experience of students and are very useful for educational purposes [4], so improvements in this area of education are important. When working in the PSP laboratories students can apply theory taught in lectures on designing the proper settings for physical relays, and observe their operation.

This paper summarizes the software-based practical experiments developed for the PSP course at Curtin University (CU), Australia. The activities and procedures described in this paper are general, however, and can be duplicated and used for PSP instruction at any institution. Not depending on a particular laboratory set-up, or on a particular manufacturer or supplier, they can be implemented on any commercially-available products and are applicable globally.

The main intended outcomes of the developed activities were to:

- inspire PSP students with the subject,

- improve students' learning experience, including handson experience and simulation designs,

- improve students' satisfaction with the course's practical laboratory activities,

- improve student total scores,

- increase student interest in taking PSP-related final-year projects (FYP) in the subsequent academic year.

The results of these activities were evaluated accordingly.

The rest of the paper is organized as follows: Section II discusses the various possibilities for, and previous work on, PSP laboratories, with a literature survey focusing on publications by academics developing PSP laboratories in their universities. The pedagogical approaches related to the activities are briefly reviewed in Section III. Sections IV to VI detail how the computer-based experimental sessions improved the learning experience for the CU PSP students, giving examples of student results with the activities. Section VII describes the evaluation of the activities through student satisfaction and comments, their scores for the course, and the number of PSP-related FYPs. Section VIII presents these evaluation results and the research findings, and Section IX draws conclusions. 


\begin{tabular}{|c|c|c|}
\hline Activity Topic & Task & Duration (weeks) \\
\hline \multicolumn{3}{|l|}{ Activity: ETAP Computer-Based Simulations } \\
\hline Introduction to ETAP & $\begin{array}{l}\text { - Draw an example of a power system in ETAP } \\
\text { - Carry out a load flow analysis for the network under consideration } \\
\text { - Carry out short-circuit analysis for the network }\end{array}$ & 2 \\
\hline $\begin{array}{l}\text { Overcurrent (OC) protection and coordination in } \\
\text { ETAP }\end{array}$ & $\begin{array}{l}\text { - Design an OC protection system for the network under consideration } \\
\text { - Design coordination between the OC relays for the network }\end{array}$ & 2 \\
\hline $\begin{array}{l}\text { Distributed Generation (DG) effects on OC protec- } \\
\text { tion }\end{array}$ & $\begin{array}{l}\text { - Investigate the performance of OC protection coordination in presence of } \\
\text { DGs }\end{array}$ & 1 \\
\hline \multicolumn{3}{|l|}{ Activity: PSCAD Computer-Based Simulations } \\
\hline Introduction to PSCAD & $\begin{array}{l}\text { - Draw an example of a power system in PSCAD } \\
\text { - Carry out short-circuit analysis for that network }\end{array}$ & 2 \\
\hline OC protection and coordination for a feeder & - Develop the OC protection for the network & 1 \\
\hline DG effects on OC protection & $\begin{array}{l}\text { - Investigate the performance of OC protection coordination in presence of } \\
\text { DGs }\end{array}$ & 1 \\
\hline Transformer differential protection & - Develop the transformer differential protection for the network & 1 \\
\hline Transmission line distance protection & - Develop the transmission line distance protection for the ne twork & 1 \\
\hline \multicolumn{3}{|c|}{ Activity: Power System Simulator-Based Experiments } \\
\hline Transformer protection & $\begin{array}{l}\text { - Perform the differential protection experiment } \\
\text { - } \text { Perform the REF protection experiment }\end{array}$ & 2 \\
\hline Induction motor protection & $\begin{array}{l}\text { - Perform the unbalance and under/over voltage protection experiment } \\
\text { - } \text { Perform the OC protection experiment }\end{array}$ & 2 \\
\hline \multicolumn{3}{|c|}{ Activity: Stand-Alone Protective Relay Experiments } \\
\hline Stand-alone relay tests with secondary injection set & $\begin{array}{l}\text { - } \text { Perform the OC and distance protection relay test } \\
\text { - } \text { Perform the differential protection relay test } \\
\text { - } \text { Perform the OC relay test with COMTRADE files }\end{array}$ & 4 \\
\hline
\end{tabular}

\section{PREVIOUS WORK ON PSP LABARATORIES}

Electrical engineering laboratories can take the form of a demonstration by a laboratory supervisor, student work following a prepared laboratory handout, a blue-box approach, a software-based approach, or a web-based approach, as discussed by [5], [6]. These same options are applicable for the PSP laboratories, whose main objective is to provide students with practical, hands-on experience of applying the concepts and theories taught in lectures to industrial protection devices.

The main difficulty in developing a PSP laboratory in universities is their limited budgets. Protection relays are very expensive, on the order of a few thousand dollars per relay, depending on features. Software simulation-based PSP laboratories, such as those developed from 1989 to 1996 as discussed in [7]-[9], are thus the best option to overcome the lack of financial support.

With the rise of the Internet, the development of remote-access laboratories started in mid-1990s [10]. For educational courses, remote-access PSP laboratories seem very appealing, mainly because of their reduced costs and their accessibility. Students at any location can connect to the laboratory computers via the Internet and re-run the activities as many times as they need [11]. These can even be students from another university, once proper arrangements and agreements are in place between the universities. Since protection relays can be tested remotely [12], a few remote PSP laboratories have been set up, such as those at the University of Adelaide, Australia [13], the Technical University of Catalonia, Spain [14] and the Polytechnic Institute of Setubal, Portugal [15]. Although students' learning experience with remote-access laboratories is educationally equivalent to that obtained in traditional laboratory activities, being physically present in the PSP laboratory to carry out experiments, discuss these with other students and with the laboratory supervisors is very important to students' learning experience [16].
As discussed in [17], [18], an industrial PSP laboratory was set up by academics in the American University of Tennessee, Chattanooga, and Drexel University, Philadelphia, with educational/industrial financial support, and using the microprocessor-based relays from Schweitzer Engineering Laboratories (SEL). A scaled-down laboratory experiment in which a computer implements an overcurrent (OC) protection strategy is described in [2], [19], and a real time digital simulator (RTDS)-based relay testing facility is presented in [20].

A real PSP laboratory was built in B.V.M. Engineering College, India, for which an educational fund purchased 107 relays [21]. The same authors have also presented a distance protection example based on their PSP facilities [22].

In a small scale PSP laboratory based on SEL relays in Portland State University, thanks to use of actual relays in the laboratories as introduced in [23], students are trained with hands-on experience in PSP, and directly prepared for entry-level engineering positions in industry. Such practical experience is increasingly valuable because there are insufficient experienced power engineers in industry.

Lack of funds prevents most universities from building a real PSP laboratory. Hence, small scale power simulators for educational purposes are of great interest. Of these, LabVolt [24], Terco [25] and Edibon [26] have the bestknown protection workstations offering the possibility of having students run protection-related experiments in the laboratory. Nevertheless, each of these workstations costs some tens of thousand of dollars.

\section{PEDAGOGICAL APPROACH}

The laboratory activities for the CU PSP course consist of computer-based simulations and practical experiments, Table I. The computer-based simulations start from the first week of the semester, with practical sessions starting in week 5 , after students have been introduced to the principles of protective relays. The various tasks students 
perform are discussed below; similar activities can be developed for PSP instruction at other institutions.

\section{A. Pre-Laboratory Assignments}

Students design the protection system and define the proper settings for a power system example in prelaboratory assignments. This mandatory activity is based on knowledge students acquire in lectures and tutorial sessions. These assignments are assessed by the laboratory supervisors at the beginning of each lab session and then validated by the students themselves through computer-based simulations or practical experiments.

\section{B. Laboratory Manuals}

Laboratory manuals list the activities to be carried out by the students during each laboratory session, and describe the step-by-step procedures, the objectives of each experiment and the expected learning outcomes. The main safety issues related to the experiments are also highlighted at the beginning of each laboratory manual. Several questions are embedded within each section of manuals to encourage the students to discuss the concepts observed.

\section{Tutorial Video Files}

A series of videos introducing the computer-based simulations were captured and edited by Echo360 software [27] and then made accessible through the university Blackboard system [28] to students enrolled in PHP, at any time from any computer/laptop or tablet with Internet access.

\section{Computer-Based Simulations and Practical Experiments}

In total, eight computer-based simulation activities and seven practical experiments were developed. Since there is a limited number of workstations, groups of students rotate through the various experiments such that each student has performed each experiment by the end of the semester. The computer-based simulation studies are presented in Section IV, and the practical experiments in Sections V and VI.

\section{E. Laboratory Assignments}

Students submit their laboratory reports online through the Blackboard system, in their various groups. The reports are assessed and marked by the laboratory supervisors, to evaluate the learning outcomes and to give feedback to each student to improve their understanding out of the activity. Course assessment is discussed in detail in Section VII.

\section{COMPUTER-BASED SOFTwARE SIMULATIONS}

A list of 42 dedicated software tools for power system analysis is reported in [29], of which about 75\% of them are commercially available. Most are available in free or very low cost educational or student versions. A few of the tools include specifically designed protection modules; well-known software tools for PSP students are ETAP [30], DIgSILENT [31], NEPLAN [32, 33], CYME [34], IPSA [35], PSCAD [36] and PSS SINCAL [37].

To give students experience on software simulations as well as practical experiments, a set of software-based simulations was developed based on the suggestions made in [38] to overcome the problems of traditional laboratory activities, and to:
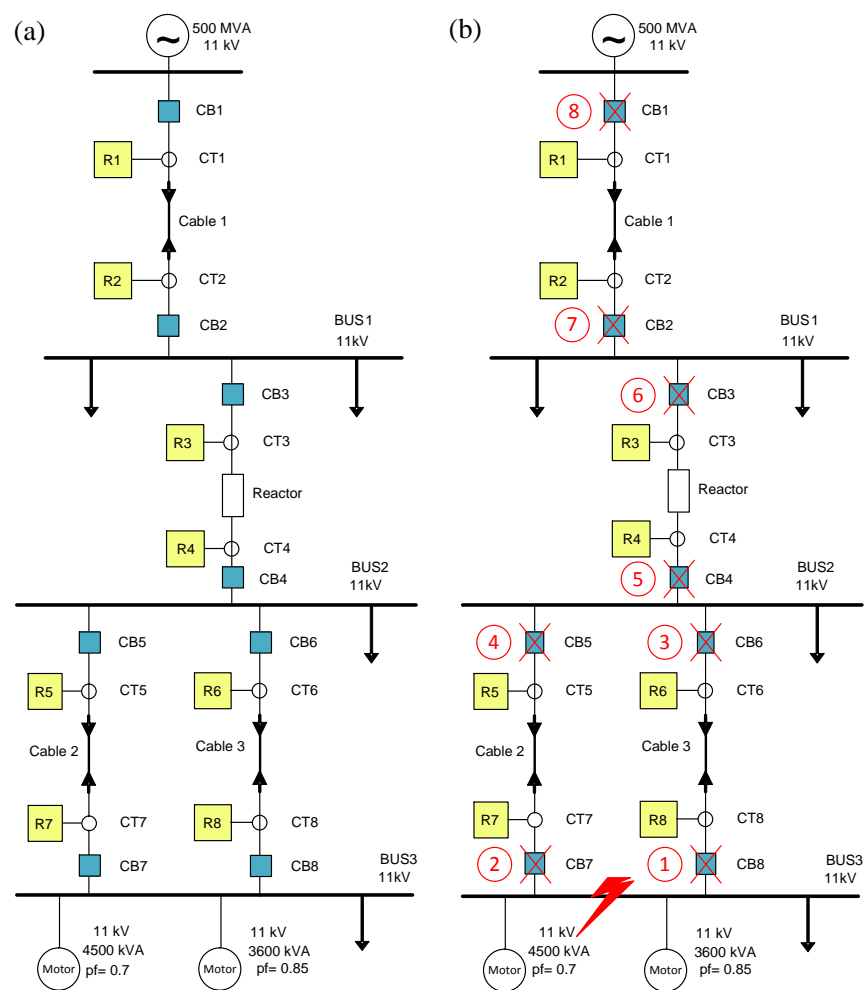

Fig. 1. (a) Sample project to be modeled and analyzed by PSP students in ETAP, to provide an appropriate OC protection system and coordination, (b) Sample student results for relay coordination.

Table II. Sample student results illustrating the operating time sequence of OC relays and circuit breakers (CBs) for the network of Fig. 1(a).

\begin{tabular}{cc|cc}
\hline Device & Time [ms] & Device & Time [ms] \\
\hline Relay-8 & 41 & CB-8 & 51 \\
Relay-7 & 41 & CB-7 & 51 \\
Relay-6 & 353 & CB-6 & 363 \\
Relay-5 & 353 & CB-5 & 363 \\
Relay-4 & 683 & CB-4 & 693 \\
Relay-3 & 1107 & CB-3 & 1117 \\
Relay-2 & 1567 & CB-2 & 1577 \\
Relay-1 & 3134 & CB-1 & 3144 \\
\hline
\end{tabular}

- promote autonomy in laboratory activities,

- develop creativity and problem-solving skills,

- motivate PSP students in carrying out their laboratory activities.

In the 2013 academic year, a series of ETAP-based videos were prepared, showing:

- the basic steps to get familiar with the software, its environment, features, modes, and so on,

- the software library and different components available, - the drawing of a single-line diagram network with the software,

- the ratings and numerical specifications for all components in the single-line diagram,

- load flow analysis, and how to build various load flow projects,

- retrieval of load flow analysis reports in different formats, and adjustment of the ratings of the conductors, busbars, circuit breakers (CB), current transformers (CT) and potential transformers (PT) based on the load flow analysis,

- short-circuit analysis, the building of various shortcircuit projects, the difference between the available standards on short-circuit calculations, how to retrieve short-circuit analysis reports in different formats, how to adjust circuit breaker ratings based on the shortcircuit analysis, 

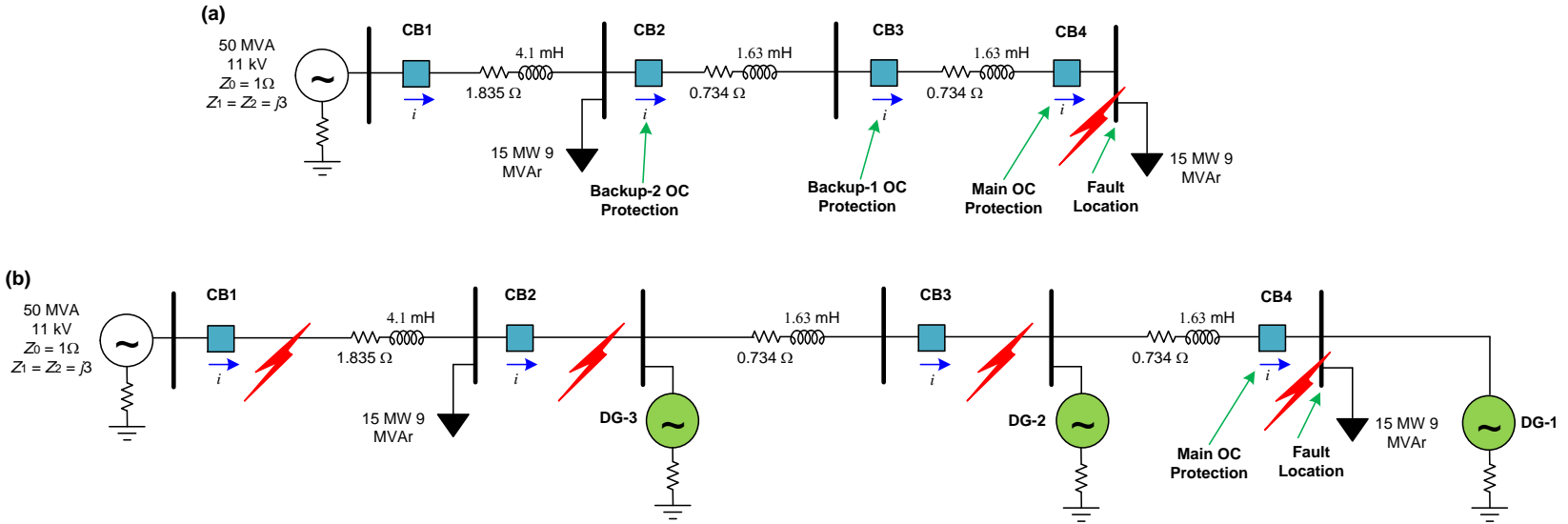

(c)

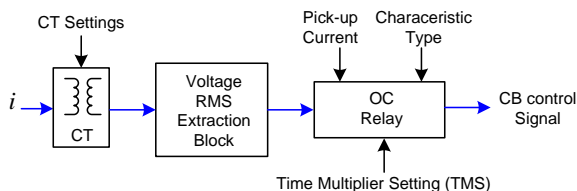

(d)

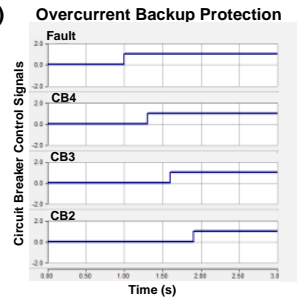

(e)

\begin{tabular}{|c|c|c|c|c|c|c|}
\hline \multirow[b]{2}{*}{10.} & \multirow[b]{2}{*}{ DG } & \multicolumn{2}{|c|}{ BRK 22} & \multicolumn{2}{|c|}{ BRK 33} & \multirow{2}{*}{$\begin{array}{c}\text { BRK } 44 \\
\text { Trip Time } \\
\text { [sec] }\end{array}$} \\
\hline & & $\begin{array}{c}\text { Trip Time } \\
\text { [sec] }\end{array}$ & $\begin{array}{l}\text { Grading Time } \\
\text { [sec] }\end{array}$ & \begin{tabular}{|c} 
Trip Time \\
[sec]
\end{tabular} & $\begin{array}{c}\text { Grading Time } \\
{[\mathrm{sec}]}\end{array}$ & \\
\hline 1 & $5 \mathrm{MW} \& 3.75 \mathrm{MVar}$ & 1.128 & 0.518 & 0.61 & 0.244 & 0.366 \\
\hline 2 & $2 \mathrm{MW} \& 1.5 \mathrm{MVar}$ & 1.128 & 0.316 & 0.812 & 0.344 & 0.468 \\
\hline 3 & $8 \mathrm{MW} \& 6 \mathrm{MVar}$ & 1.128 & 0.568 & 0.56 & 0.24 & 0.32 \\
\hline 4 & $5 \mathrm{MW} \& 3.75 \mathrm{MVar}$ & 1.128 & 0.5109 & 0.6171 & 0.2511 & 0.366 \\
\hline 5 & $5 \mathrm{MW} \& 3.75 \mathrm{MVar}$ & 1.128 & 0.511 & 0.617 & 0.251 & 0.366 \\
\hline
\end{tabular}

Fig. 2. (a) Sample project to be modeled and analyzed by PSP students in PSCAD to develop an OC protection system and coordination, (b) Sample project to be modeled and analyzed in PSCAD to observe the effect of the presence of DG units on the coordination of the OC relays, (c) Procedure for interconnection of a relay to the relevant CT and CB in PSCAD, (d) Sample student results illustrating the main and backup OC relays operation after a fault in the considered system, (e) Sample student results obtained summarizing the OC protection operating time for a fault, considering different generation levels for a DG in the system of Fig. 2(b).

- design of proper settings for the OC relays and linking them to the CTs and CBs, selecting proper options from the available models in ETAP library, defining time multiplier settings (TMS) and pickup levels for the relays,

- protection coordination for the OC relays, adjusting the relays operating time to provide proper backup system for each relay, plotting the time curve characteristics (TCC) for the relays of one bay,

- differential protection adjustment for the transformers in the single-line diagram.

Fig. 1(a) shows a project that students designed and analyzed using the load flow, short-circuit and protection coordination capabilities of ETAP. Fig. 1(b) shows the coordination results for a fault at bus- 3 of the system. The operating times for the relays and the CBs are listed in Table II.

Since ETAP has no distance protection capability in its current version (v.12), DIgSILENT and Neplan software should be used to carry out the distance protection experiments. Similar software-based activities for PSP instruction can be developed at other institutions.

The above simulation study helps students to understand and visualize short-circuit studies and protection issues from a steady-state point of view. To observe the time-domain operation, PSCAD-based simulations were developed, and introduced in the 2014 academic year. These simulations demonstrate the differential protection of a transformer, the distance protection of a transmission network and the OC protection and coordination of a distribution feeder. As an example, a snapshot of a feeder used for OC protection and coordination is shown in Fig. 2(a). After proper design of the main and backup OC protection for a fault at a given bus, a fault is applied at that specific bus and the coordination of the relays is observed in the time domain.
To integrate the new topic of distributed generation (DG), two case studies were developed - one in ETAP and the other in PSCAD. These demonstrate how a network with proper OC relay coordination is affected after the interconnection of the DGs, as a function of their ratings and installation at different buses. As an example, Fig. 2(b) shows a power system with three DG units at different buses, modeled in PSCAD. Fig. 2(c) illustrates the OC relay connections from the CTs to the CBs in these examples. Fig. 2(d) shows a student result for the system of Fig. $2(\mathrm{a})$, for a three-phase to ground fault at $t=1 \mathrm{~s}$ at bus- 4 , in which the main OC protection operates at $t=1.3 \mathrm{~s}$ while the backups operate with a desired $0.3 \mathrm{~s}$ time margin. Fig. 2(e) shows the students' table based on the summarized OC protection operating time data for a fault at a given point, considering different generation levels for the DGs. Students calculated and listed the tripping time of each relay in this table. The grading time between each relay and its backup protection is also calculated and listed. The students then analyze the grading times. As an example, the grading time between CB-3 and CB-4 in Fig. 2(b) for a considered case becomes $0.24 \mathrm{~s}$ (unsatisfied) when DG-1 generates $5 \mathrm{MW}$ and 3.75 MVAr, while it becomes $0.344 \mathrm{~s}$ (satisfied) when the DG generates $2 \mathrm{MW}$ and $1.5 \mathrm{MVAr}$. The students are requested to highlight the sections of the table in which a coordination mismatch is detected due to the interconnection of DGs in the network. This example helps the students to realize that connection of DGs may adversely affect the $\mathrm{OC}$ protection scheme.

The main educational procedure for the software-based simulations is to use the recorded videos, so students can attend more experimental laboratory activities throughout the semester without increasing the official contact hours for the course. 

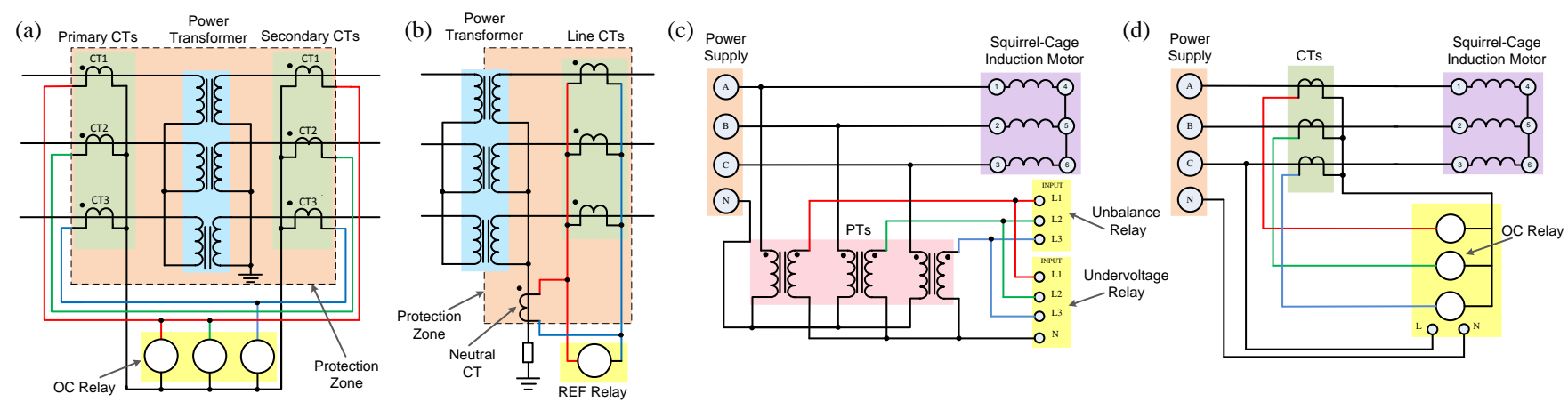

Fig. 3. Schematic diagram of the experiment for (a) differential protection of the transformer, (b) REF protection of the transformer, (c) unbalance and under/over voltage protection for the induction motor, (d) OC protection for the induction motor.

Table III. Sample student results demonstrating the current monitored at the primary and secondary of the power transformer, and by the OC relays in each phase [mA] during transformer differential protection experiment.

\begin{tabular}{|c|c|c|c|c|c|c|c|c|c|c|c|}
\hline & \multicolumn{2}{|c|}{ Phase-a current } & \multicolumn{2}{|c|}{ Phase-b current } & \multicolumn{2}{|c|}{ Phase-c current } & \multicolumn{3}{|c|}{ OC Relay } & \multicolumn{2}{|c|}{ Relay Operation } \\
\hline & Prim. & Sec. & Prim. & Sec. & Prim. & Sec. & Phase-a & Phase-b & Phase-c & Must Trip & Tripped? \\
\hline No Fault & 315 & 301 & 314 & 302 & 319 & 300 & 240 & 206 & 243 & No & No \\
\hline Phase-a to ground fault & 328 & 286 & 318 & 308 & 322 & 306 & 459 & 156 & 275 & Yes & Yes \\
\hline Phase-a to c fault within protection zone & 718 & 694 & 325 & 303 & 757 & 763 & 5530 & 371 & 5410 & Yes & Yes \\
\hline Phase-a to c fault outside protection zone & 779 & 756 & 315 & 300 & 771 & 771 & 206 & 211 & 198 & No & No \\
\hline
\end{tabular}

Table IV. Sample student results demonstrating the current monitored at the primary and secondary of the power transformer in each phase and by the neutral CT and the REF relay [mA] during the restricted earth fault protection experiment.

\begin{tabular}{|c|c|c|c|c|c|c|c|c|c|c|}
\hline & \multicolumn{2}{|c|}{ Phase-a current } & \multicolumn{2}{|c|}{ Phase-b current } & \multicolumn{2}{|c|}{ Phase-c current } & \multirow[t]{2}{*}{ Neutral current } & \multirow[t]{2}{*}{ REF Relay } & \multicolumn{2}{|c|}{ Relay Operation } \\
\hline & Prim. & Sec. & Prim. & Sec. & Prim. & Sec. & & & Must Trip & Tripped? \\
\hline No Fault & 321 & 304 & 320 & 309 & 321 & 304 & 39 & 4 & No & No \\
\hline Phase-a to ground fault & 336 & 295 & 334 & 314 & 328 & 308 & 42 & 409 & Yes & Yes \\
\hline Phase-a to c fault within protection zone & 1010 & 1004 & 657 & 472 & 505 & 436 & 391 & 9980 & Yes & Yes \\
\hline Phase-a to c fault outside protection zone & 991 & 981 & 644 & 466 & 499 & 440 & 366 & 4 & No & No \\
\hline
\end{tabular}

\section{EXPERIMENTS USING POWER SYSTEM SIMULATOR}

The experiments are based on the LabVolt power system simulator. In the 2013 academic year, only the educational relays available in the LabVolt workstation were used, but in academic year 2014, these were replaced by industrial SEL relays to provide students with a better hands-on experience. The SEL relays are already configured; students only need to insert the numerical settings that they had calculated in the pre-laboratory assignments.

The main difficulties encountered in developing the laboratory were:

- arranging the budget to purchase new equipment and relays,

- the significant amount of time spent configuring the relays, installing of the devices, and developing the laboratory experiments and laboratory manuals,

- assessing and mitigating the health and safety risks associated with the experiments,

- training laboratory supervisors for the new experiments.

The laboratory experiments, discussed briefly below, are intended to help students visualize and understand:

- the differential protection of transformers,

- the restricted earth fault (REF) protection of transformers,

- the phase unbalance and under/over voltage protection of induction motors, and

- the OC protection of induction motors.

The developed experiments are discussed briefly below:

\section{A. Differential Protection of Transformers}

Differential protection is based on the fact that under normal conditions the currents in the secondary of the CTs located at the two sides of the transformer are equal. Therefore, the difference of these two currents passing through the differential protection relay is zero. During a fault within the differential protection zone, this current difference is nonzero and the protection relay trips.

Fig. 3(a) shows the schematic diagram of the differential protection used for the transformer. This protection is applied for a LabVolt fault-able three-phase transformer. Phase-tophase and phase-to-ground faults are applied in the transformer windings and inside the protected zone. An overcurrent educational relay module is used to trip the circuit once its current becomes higher than a small pre-defined value. Since the LabVolt educational relays do not have harmonic restraint and blocking functions (similar to those in industrial differential relays), to prevent relay tripping due to the transformer start-up (inrush) current, a small pick-up time setting is chosen such that the relay trips for faults but does not trip for inrush currents. Once the educational relays were replaced by industrial differential relays (e.g., SEL 487), the harmonic restraint and blocking function prevented the unwanted relay tripping for transformer inrush currents.

The experiment is repeated for a fault outside the differential protection zone and it is demonstrated that the differential protection does not trip for the faults outside the zone. Typical student results, Table III, show the current monitored at the primary (prim.) and secondary (sec.) of the power transformer and also the current sensed by the OC relays in each phase during the experiment. Note that small discrepancies may be observed in the results due to variations in accuracy and sensitivity of the ammeters used.

\section{B. REF Protection of Transformers}

REF protection is a complementary scheme for transformer differential protection. Fig. 3(b) shows the schematic diagram of the REF protection used for a transformer. This protection is applied for a LabVolt fault-able three-phase transformer with a star-grounded connection. A phase-to-ground fault is applied in the transformer secondary windings. A total of four CTs are used - three to monitor the three-phase secondary 
(a)

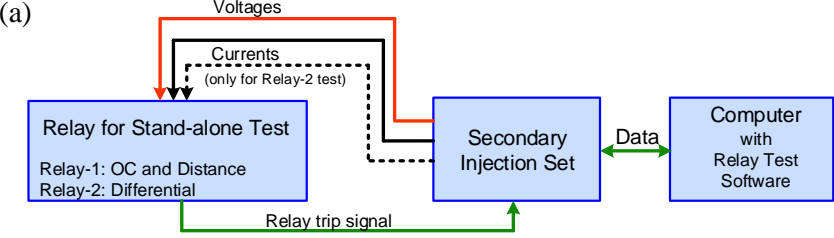

(b) 10000.00

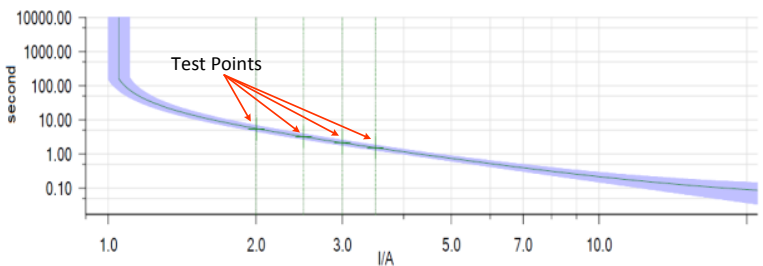

(c)

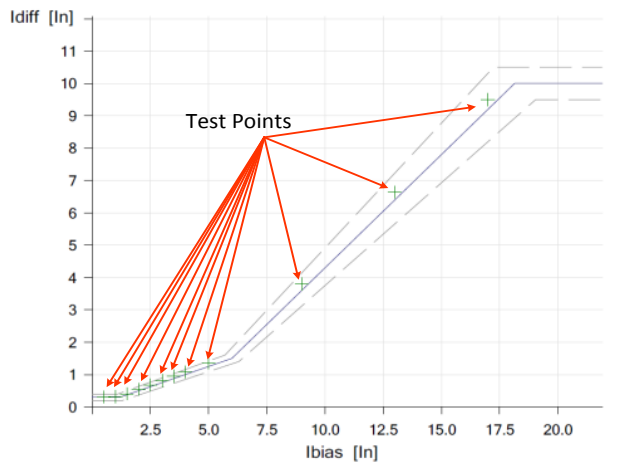

Table V. Typical OC relay test results with secondary injection set.

\begin{tabular}{|c|c|c|c|c|c|c|c|}
\hline \multirow{2}{*}{\multicolumn{2}{|c|}{$\begin{array}{c}\text { Current } \\
\text { [A] }\end{array}$}} & \multicolumn{6}{|c|}{ Operating time $[\mathrm{s}]$} \\
\hline & & \multicolumn{2}{|c|}{ Minimum } & \multicolumn{2}{|c|}{ Maximum } & \multicolumn{2}{|c|}{ Expected } \\
\hline \multicolumn{2}{|c|}{2} & \multicolumn{2}{|c|}{4.728} & \multicolumn{2}{|c|}{6.811} & \multicolumn{2}{|c|}{5.65} \\
\hline \multicolumn{2}{|c|}{3} & \multicolumn{2}{|c|}{1.836} & \multicolumn{2}{|c|}{2.529} & \multicolumn{2}{|c|}{2.15} \\
\hline $\begin{array}{l}\text { Fault } \\
\text { type }\end{array}$ & $\begin{array}{c}\text { Cur- } \\
\text { rent } \\
{[\mathrm{A}]}\end{array}$ & $\begin{array}{l}\text { Meas- } \\
\text { ured } \\
\text { time [s] }\end{array}$ & Result & $\begin{array}{l}\text { Fault } \\
\text { type }\end{array}$ & $\begin{array}{l}\text { Cur- } \\
\text { rent } \\
{[\mathrm{A}]}\end{array}$ & $\begin{array}{c}\text { Measured } \\
\text { time }[\mathrm{s}]\end{array}$ & Result \\
\hline \multirow{2}{*}{$A-G$} & 2 & 5.670 & Passed & \multirow{2}{*}{$A-B$} & 2 & 5.665 & Passed \\
\hline & 3 & 2.175 & Passed & & 3 & 2.161 & Passed \\
\hline \multirow{2}{*}{$B-G$} & 2 & 5.671 & Passed & \multirow{2}{*}{$\mathrm{B}-\mathrm{C}$} & 2 & 5.669 & Passed \\
\hline & 3 & 2.157 & Passed & & 3 & 2.156 & Passed \\
\hline \multirow{2}{*}{$\mathrm{C}-\mathrm{G}$} & 2 & 5.655 & Passed & \multirow{2}{*}{$\mathrm{A}-\mathrm{C}$} & 2 & 5.644 & Passed \\
\hline & 3 & 2.158 & Passed & & 3 & 2.159 & Passed \\
\hline A-B-C & 2 & 5.643 & Passed & A-B-C & 3 & 2.160 & Passed \\
\hline
\end{tabular}

Table VI. Typical differential relay test results with secondary injection set.

\begin{tabular}{|c|c|c|c|c|}
\hline \multirow{2}{*}{ Fault type } & \multirow{2}{*}{$I_{\text {bias }}[\mathrm{A}]$} & \multicolumn{2}{|c|}{$\begin{array}{l}\text { Current Difference between Pri- } \\
\text { mary and Secondary [A] }\end{array}$} & \multirow{2}{*}{ Result } \\
\hline & & Relay Trip Limit & Tested Value & \\
\hline \multirow{4}{*}{ A-B } & 1 & 0.3 & 0.316 & Passed \\
\hline & 3 & 0.75 & 0.809 & Passed \\
\hline & 5 & 1.25 & 1.357 & Passed \\
\hline & 10 & 4.3 & 4.517 & Passed \\
\hline \multirow{4}{*}{ B-G } & 1 & 0.3 & 0.316 & Passed \\
\hline & 3 & 0.75 & 0.814 & Passed \\
\hline & 5 & 1.25 & 1.355 & Passed \\
\hline & 13 & 3.7 & 4.052 & Passed \\
\hline \multirow{4}{*}{ A-B-C } & 1 & 0.3 & 0.316 & Passed \\
\hline & 3 & 0.75 & 0.809 & Passed \\
\hline & 5 & 1.25 & 1.357 & Passed \\
\hline & 17 & 9.2 & 9.493 & Passed \\
\hline
\end{tabular}

To apply a voltage unbalance to the motor, one of the three-phase power supply connections is disconnected. In this case, the voltage unbalance relay picks up the unbalance as soon as it exceeds the setting of the relay and trips the circuit after the pre-defined time period. It is to be noted that due to the phase loss, both the undervoltage relay and the voltage unbalance relay pick up the fault. However, they trip at different time periods, based on their pre-defined time settings.

The last experiment for this setup is to apply the threephase voltage in a reverse sequence. For this, any arbitrary two phases of the three-phase power supply output are interchanged. Hence, the unbalance relay picks up the reverse rotation of the motor from the reverse sequences of the voltages and trips the circuit after the specified time. Note that proper bypassing switches are used to bypass the relay during the changes in the experiments.

\section{OC Protection of Induction Motors}

Fig. 3(d) shows the schematic diagram for OC protection of an induction motor. This protection is applied for a LabVolt squirrel cage three-phase induction motor, using an educational three-phase OC relay. The motor is loaded by a LabVolt electrometric load.

The OC relay picks up whenever the monitored current exceeds the pre-defined pick-up limit of the relay and trips the circuit after a pre-defined time period. The time setting of the relay is chosen such that the circuit is not tripped by the OC relay at the initial starting time of the motor. 


\section{STAND-AlONE RELAY TEST EXPERIMENTS}

In addition to the power simulator-based experiments, two different stand-alone tests are implemented for the relays.

In the first experiment, a secondary injection set of Omicron CMC356 [39] is used to test one SEL321 (OC and distance) protection relay and one SEL487 (transformer differential) protection relay. The two relays are already configured and some settings are applied to them. This test system is illustrated in Fig. 4(a). The main objective of this experiment is to introduce students to the fundamentals of relay testing and commissioning procedure. It is to be noted that other injection sets such as Ponovo [40] may be a more affordable option for the PSP laboratories of universities.

Table $\mathrm{V}$ gives typical results of $\mathrm{OC}$ relay tests carried out by students. The tested relay is assumed to have an extremely inverse characteristic, with a pick-up current of $1 \mathrm{~A}$ and a tolerance of 5\%. The relay is tested under phase-to-ground, phase-to-phase and three-phase faults with a current magnitude of 2, 2.5, 3 and 3.5 A. The expected and measured relay operating times are given in Table $\mathrm{V}$ for some of these tests. Fig. 4(b) illustrates the TCC of the tested relay along with these test points for one of a three-phase fault test.

Table VI illustrates a sample differential relay test results carried out by the students. The tested relay is assumed to operate with a differential pick-up current of $0.3 \mathrm{~A}$ after a delay time of $0.02 \mathrm{~s}$ and a tolerance of $1 \%$. The relay is tested under phase-to-ground, phase-to-phase and three-phase faults for 11 differential current magnitudes. The expected and measured relay operating times are given in Table VI for some of these tests. Fig. 4(c) illustrates the operating characteristic diagram of the tested relay along with these test points for a single-phase to ground fault.

The second stand-alone test experiment is based on testing a relay, with specified configurations and settings but with a COMTRADE file, saved from PSCAD simulations. In this experiment, a power system is simulated in PSCAD and the current and voltage time-domain waveforms during a fault at the relay location are stored as a COMTRADE file. This file is later imported by OMICRON software and the same currents and voltages are generated by the injection set and applied to the relay. This test, conducted by PSP students from academic year 2014 onwards, demonstrates whether a relay with the student-defined settings would operate successfully for that fault in reality.

\section{STUDENT ASSESSMENT}

Student grades for the PSP course are weighted at 50\% final examination, $30 \%$ design assignment and $20 \%$ laboratory assignments. Half of the laboratory assignment mark is for the report on simulation-based activities and the rest is for the report on the practical experiments. To minimize student workload, only two laboratory reports (one simulation-based and one practical-based) are required, at the end of the semester.

In the simulation-based laboratory report, students must model, design and analyze a given network in ETAP and PSCAD; calculate the proper settings for the components; run some load flow and short-circuit analysis tests; and then summarize the results in a table or figure. Finally, they must provide a short discussion on the main outcomes of the project, and what they have understood from it.

The practical-based laboratory report is a survey of all the semester's practical experiments. Students need to briefly explain the experiments, discuss the mechanism of different protection schemes and explain the procedure for applying each protection scheme. They must also answer the questions in the laboratory manuals, and highlighting their main observations from the activities.

Students submit their laboratory reports online through the Blackboard system, in their groups. A detailed rubric is prepared for the laboratory supervisors to refer to when marking the laboratory reports. To provide better feedback to students, the laboratory supervisors comment on each laboratory report using the Adobe Acrobat Commenting tool [41], which allows them to highlight mistakes and correct calculations/assumptions throughout the text. In addition, the laboratory supervisors add a voice comment on each laboratory report that serves as the main feedback to the students.

\section{EVALUATION AND FINDINGS}

In this section, the effects of the laboratory activities are presented and discussed. First, student satisfaction was analyzed from official evaluation results carried out by Curtin University [42]. Then, a comparison was made of the total scores of the students in this course. The satisfaction and total scores of the students were compared for the periods before the laboratory development (i.e., academic year 2011) and after the finalization of the laboratory development (i.e., academic year 2014). Finally, student interest in taking PSPrelated subjects for their FYPs in the semester after completing this course is discussed.

\section{A. Comparison of Student Satisfaction}

Until 2012, the CU PSP course had only one practical and two ETAP-based software activities. The practical laboratory session was used for demonstration purposes only; students carried out no activity, but only observed the laboratory supervisor running a pre-configured and pre-connected test in the laboratory. The students enrolled in PSP in 2011 described the laboratory activities as "useless" and "not wellorganized" when replying to the "how you think the course might be improved?" question from the official university evaluation, and preferred to have more "practical" activities.

During 2013-2014, the students praised the laboratory activities as being "useful", "well-designed", "fairly practical" and "constructive" under the "most helpful aspects of the course" question within the university official evaluation. A few sample comments from students are provided in Table VII for these periods.

In addition to the comments, the students rank their level of agreement or disagreement with several pre-defined statements about a course within the university official evaluations. Table VIII lists the four statements related to the laboratory activities. A comparison between the agreement levels of students for these statements is shown in Fig. 5(a) for the periods before and after the PSP laboratory development, based on 48 students enrolled in 2011 and 72 students enrolled in 2014, with a response rate of the students was $40 \%$ and $47 \%$ respectively. Note that the lectures and tutorial sessions were conducted in both years by the same lecturer and had negligible changes in other teaching material (i.e., lecture notes and tutorial sets). From this figure, it can be seen that a $15 \%$ increase in student satisfaction is observed for their motivation in the course. Furthermore, a $9 \%$ increase is observed in the satisfaction of students for their ability to make best use of the course learning experience. Moreover, despite the incr- 
Table VII. A sample of student comments before the development of the laboratory activities (in 2011) and after (in 2013-14).

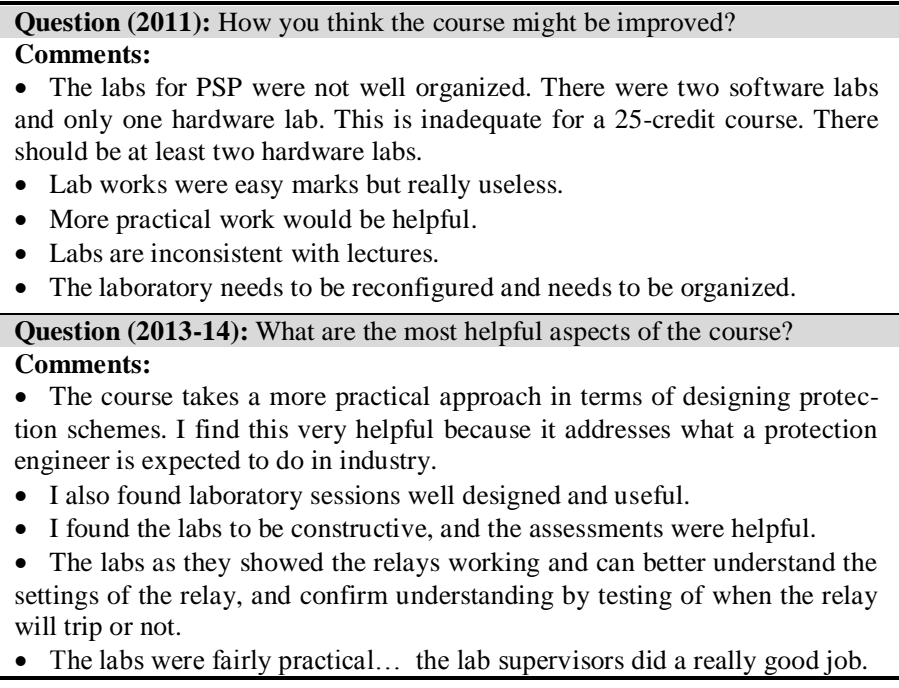

Table VIII. Pre-defined statements from the official university evaluation for student agreement/disagreement.

S1: The quality of teaching in this course helps me to achieve the learning outcomes.

S2: I am motivated to achieve the learning outcomes in this course.

S3: I make best use of the learning experiences in this course.

S4: The workload in this course is appropriate to the achievement of the learning outcomes.

eased workload, a $12 \%$ increase is observed in the satisfaction of the students regarding the appropriateness of the workload.

\section{B. Comparison of Student Scores}

The students demonstrate more interest in the PSP course after attending the computer-based and practical-based laboratory activities. Observing the operation of the protection devices and verifying the accuracy of their designs through simulations and practical activities also improves students' knowledge retention. As a result, the total scores of the students for the PSP course improved. A comparison between the total scores of the students before and after the laboratory development is shown in Fig. 5(b). This figure demonstrates that before the laboratory development, $57 \%$ of students had a total score in the range of $50-70 \%$ while only $36 \%$ of the students had a total score in the range of 70-90\%. After the laboratory development, only $13 \%$ of the students had a total score in the range of $50-70 \%$ while $69 \%$ of the students had a total score in the range of $70-90 \%$. Note that since the course assessment level and method were kept unchanged in these two periods, the increased average of the total scores is mainly due to the laboratory activities.

\section{Comparison of Student Inspiration for PSP}

The undergraduate and Master's-by-coursework CU students have to carry out a final-year project (FYP) in the last year of their studies. Those studying electrical power engineering can choose a project under the main topics of power systems, power electronics, power quality, renewable energies, high voltage and condition monitoring, electrical machines, smart grid and PSP.

Due to the improved learning experiences in PSP course, students demonstrated a high level of interest in carrying out their FYP on PSP-related topics. Fig. 5(c) illustrates the ratio of the PSP-related FYPs with respect to the total number of FYPs of electrical power engineering students. This figure
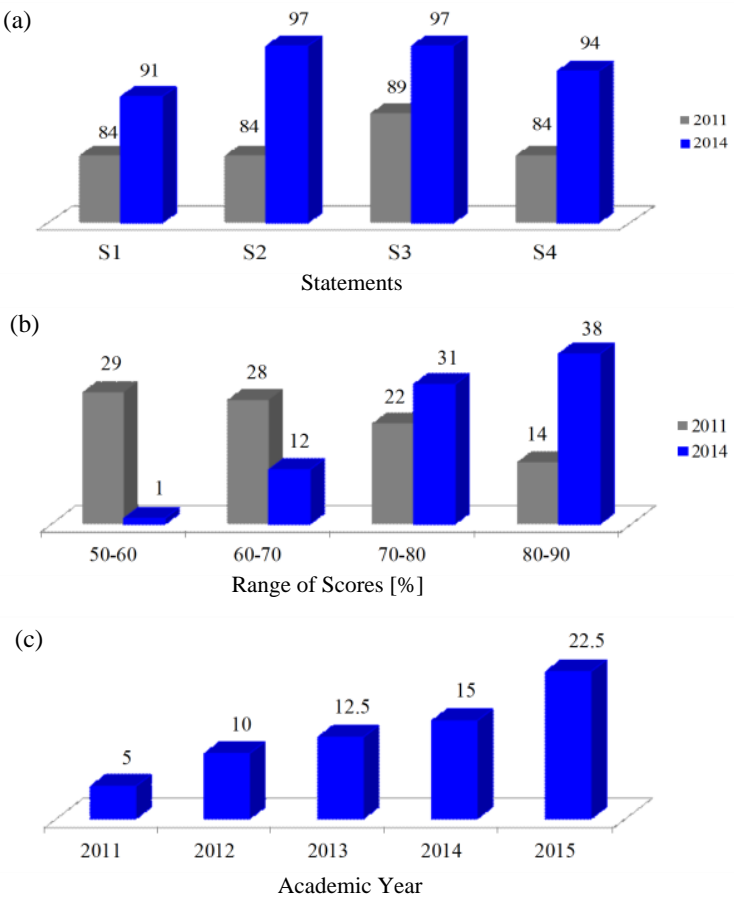

Fig. 5. (a) Satisfaction level [\%] of PSP course students for different statements in the official university evaluations before and after development of the PSP laboratory activities, (b) Distribution of the total scores of the PSP course students [\%], (c) Ratio of PSP-related FYPs by undergraduate and master by coursework students at Curtin University with respect to other subjects [\%].

illustrates a steady increase in the ratio of PSP-related FYPs during the period that PSP laboratory development was initiated and finalized (i.e., 2012-14). As can be seen from this figure, $22.5 \%$ of all FYPs on electrical power engineering were on PSP-related subjects in 2015 and the rest on one of the other seven major topics. This figure shows that the number of FYPs on PSP-related subjects is $450 \%$ higher in 2015 than 2011.

It is worth mentioning that job market and industry demand can also motivate students towards a subject. Based on Engineers Australia Fact Sheet published in January 2015, conditions in the Australian engineering market continue to be poor since 2012, with little grounds for optimism [43], and the number of engineering job vacancies in majority of Australian states has reduced in the last few years [44]. This research demonstrates that despite the unpleasant conditions in the job market and lack of significant changes in the demand level for protection engineers in the last few years, students are motivated towards PSP by the activities.

\section{Limitations}

The previous three subsections provide an assessment on the impact of the methods developed for the CU PSP students, from 2011 to 2015. These findings are contextual for CU students in particular, and in general for Western Australia; they may not be broadly applicable to all PSP course students of all institutions. However, it is expected that the students' satisfaction and total scores will be improved and they will be inspired towards PSP course by such activities, although the level of improvement might differ between institutions.

\section{CONCLUSION}

Computer-based simulations and practical experiments developed for the PSP course at Curtin University, have been presented. These can be developed and applied at other insti- 
tutions. The main objective of the activities is to improve the learning experience of students enrolled in the course. They familiarize students with network modeling, load flow, short circuit analysis and OC protection and coordination in ETAP. Students visualize the time domain fault results with OC, distance and differential protections in PSCAD. They implement differential and REF protection for the transformer as well as the OC, under/over voltage and phase unbalance protections for the induction motor in the laboratory, using a LabVolt power system simulator. An Omicron secondary injection test set is also used to test the configurations and settings of OC, distance and differential protection relays.

Incorporating these simulation-based and practical-based activities within the course learning activities makes PSP learning more interesting, motivating and understandable for the students and improves their knowledge retention. The major improvements achieved and observed through this research are in students' visualization and interaction, and in students training with practical equipment and students learning from their own experiences.

Through these activities, students became more interested in the PSP course, praised the activities in the official evaluation reports and were inspired to take their FYPs in this area. Additionally, the number of students achieving high scores increased. Student feedback and assessment data indicate that the intended objectives were achieved.

It is hoped that the information provided in this paper can assist the lecturers of PSP courses to develop similar techniques to improve student learning experiences and motivating students towards PSP-related subjects.

\section{ACKNOWLEDGEMENT}

The authors would like to thank Mr. Wayne Garrett and SEL Australia for donating the SEL relays to the PSP laboratory of Curtin University, Ms. Maryam Khallaghi and Omicron Australia for their generous supports on the Omicron relay test set, Mr. Michael Schilpzand at Voltex Power Engineers and ETAP for generously providing the educational license of ETAP to Curtin University, Dr. Dharshana Muthumuni at Manitoba HVDC Research Center for sharing his knowledge and useful notes on PSCAD application for PSP, and all the technical staff within the Department of Electrical and Computer Engineering at Curtin University for installation of the new equipment. The authors also gratefully thank the anonymous reviewers and editors of the IEEE Transactions on Education for their valuable comments and suggestions to improve the quality of the paper.

\section{REFERENCES}

[1] B. Oza, N.K. Nair, R. Mehta and V. Makwana, Power system protection and switchgear, McGraw Hill, 2010.

[2] W.J. Lee, J.C. Gu, R.J. Li and P. Didsayabutra, “A physical laboratory for protective relay education," IEEE Trans. on Education, vol. 45, no. 2, pp. 182-186, May 2002.

[3]S. Brahma, J. De La Ree, J. Gers, et al. "The education and training of future protection engineers: challenges, opportunities, and solutions," IEEE Trans. on Power Delivery, vol. 24, Issue 2, pp. 538-544, 2009.

[4]L.D. Feisel and A.J. Rosa, "The role of the laboratory in undergraduate engineering education," Journal of Engineering Education, pp. 121-130, Jan. 2005.

[5]P.I. Muoka, M.E. Haque, A. Gargoom and M. Negnetvitsky, "DSP-based hands-on laboratory experiments for photovoltaic power systems," IEEE Trans. on Education, vol. 58, no. 1, pp. 39-47, Feb. 2015.

[6]C. hoi and M. Saeedifard, "An educational laboratory for digital control and rapid prototyping of power electronic circuits," IEEE Trans. on Education, vol. 55, no. 2, pp. 263-270, May 2012.

[7]M.A. Redfern, R.K. Aggarwal and G.C. Massey, "Interactive power system simulation for the laboratory evaluation of power system protection relays," Int. Conf. on Development of Power System Protection, pp. 215-219, 1989.

[8] T.S. Sidhu and M.S. Sachdev, "Laboratory setup for teaching and research in computer-based power system protection," Int. Conf. on Energy Management and Power Delivery, vol. 2, pp. 474-479, 1995.

[9] M.S. Sachdev and T.S. Sidhu, "Laboratory for research and teaching of microprocessor-based power system protection," IEEE Trans. on Power Systems, vol. 11, no. 2, pp. 613-619, May 1996.

[10] J. Trevelyan, "Lessons learned from 10 years experience with remote laboratories," in Proc. of the Int. Conf. on Engineering Education and Research, 2004.

[11] A. Maiti and B. Tripathy, "Remote laboratories: Design of experiments and their web implementation," Educational Technology and Society, vol. 16 , no. 3, pp. 220-233, 2013.

[12] M. Musaruddin, M. Zaporoshenko and R. Zivanovic, "Remote protective relay testing," in Proc. of $18^{\text {th }}$ Australasian Universities Power Engineering Conf. (AUPEC), 2008.

[13] R. Zivanovic, "Setting and testing SEL710 via remote relay test system," Collaborative Power Engineering Centers of Excellence, Australian Power Institute, 2010.

[14] R.P. Martinez, R.V. Robles, P.L. Gallego, et al. "Protection system remote laboratory," in Proc. of the $11^{\text {th }}$ Int. Conf. on Electrical Power Quality and Utilization (EPQU), pp. 1-6, 2011.

[15] V.F. Pires, L.S. Martins, T.G. Amaral, et al. "Distance-learning power system protection based on testing protective relays," IEEE Trans. on Industrial Electronics, vol. 55, Issue 6, pp. 2433-2438, 2008.

[16] A.A. Kist, "Barriers to adopting remote access laboratory learning activities," in Proc. of the Annual Conf. of Australasian Association for Engineering Education (AAEE), 2012.

[17] A.H. Eltom, and R. Harnchotipun, "Microprocessor-based relay laboratory with industry support," in Proc. of IEEE Power Engineering Society Summer Meeting, vol. 3, pp. 1457-1461, 2002.

[18] S.P. Carullo and C.O. Nwankpa, "Interconnected power systems laboratory: a computer automated instructional facility for power system experiments," IEEE Trans. on Power Systems, vol. 17, Issue 2, pp. 215 $222,2002$.

[19] S.M.L. Kabir, "Computer operated coordinated over-current protection scheme," in Proc. of the Universities Power Engineering Conf. (UPEC), pp. 79-83, 2000 .

[20] P.G. McLaren, R. Kuffel, R. Wierckx, et al. "A real time digital simulator for testing relays," IEEE Trans. on Power Delivery, vol. 7, no. 1, pp. 207-213, 1992

[21] B.A. Oza and S.M. Brahma, "Development of power system protection laboratory through senior design projects," IEEE Trans. on Power Systems, vol. 20, Issue 2, pp. 532-537, 2005.

[22] R. Mehta, B. Oza, N.K.C. Nair and M. Kumar, "Simulation of numerical distance protection through senior design project," in Proc. of IEEE Int. Conf. on Power System Technology (POWERCON), pp. 1-6, 2012.

[23] J. Ferris and R.B. Bass, "A power systems protection teaching laboratory for undergraduate and graduate power engineering education," $120^{\text {th }}$ American Society for Engineering Education (ASEE) Annual Conf. and Exp., pp. 1-8, 2013.

[24] $0.2 \mathrm{~kW}$ Protective Relaying Training System, Model 8007, (available on June 18, 2015) https://www.labvolt.com/downloads/dsa8007.pdf

[25] Transmission Line, Transformer \& Protection Laboratory, (available on June 18, 2015) http://www.tercosweden.com/wpcontent/uploads/2009/06/transmissions_line_transformer_protective_relays.pdf

[26] ERP-UB. Protection Relays Test Unit (available on June 18, 2015) http://www.edibon.com/products/catalogues/pt/units/energy/relaysunits/ERP.pdf

[27] Echo360 Active Learning Website, (available on June 18, 2015) http://echo360.com/

[28] Blackboard Inc. Website, (available on June 18, 2015) http://anz.blackboard.com/sites/international/globalmaster/

[29] Power Systems Analysis Software, Wikipedia, (available on June 18, 2015)

http://www.openelectrical.org/wiki/index.php?title=Power_Systems_Analysis_So ftware

[30] Star-Protection and Device Coordination Catalogue, ETAP, (available on June 18,2015 ) http://etap.com/downloads/brochures/star_artts.pdf

[31] DIgSILENT PowerFactory Power System Analysis Catalogue, (available on June 18, 2015) http://www.albanah.org/ss/attachment.php?attachmentid=352

[32] Selectivity Analysis Catalogue, NEPLAN, (available on June 18, 2015) http://www.neplan.ch/html/e/pdf_e/NEPLAN_B05_SelectivityAnalysis_engl.pdf

[33] Distance Protection Catalogue, NEPLAN, (available on June 18, 2015) http://www.neplan.ch/html/e/pdf_e/NEPLAN_B06_DistanceProtection_engl.pdf

[34] Protective Device Coordination with CYME and CYMDIST, CYME, (available on June 18, 2015) 
http://www.ipet-co.com/en/download/cymecymtcc/B1100-09076-EmbeddedCYMTCC.pdf

[35] Protection Grading, IPSA, (available on June 18, 2015)

http://www.ipsa-power.com/software/ipsa-2-1/protection-grading

[36] Applications of PSCAD/EMTDC, Manitoba HVDC Research Inc. (available on June 18, 2015)

http://www.ien.pw.edu.pl/install/PSCAD/PSCAD\%204.2.1_Professional\%20+\%2

OLiveWire \%202.3_zakup\%20z\%20grantu-

2008/Install/PSCADV4/Help/HelpManuals/Application\%20Guide\%202007.pdf

[37] PSS SINCAL Platform 10.5 Release Information, Siemens, (available on June 18, 2015

http://sincal.s3.amazonaws.com/10.5/ReleaseNotes-

Eng.pdf?AWSAccess KeyId=05D315V4JJ99N5PASW02\&Expires $=1451606400$ \&Signature=MymTUdooljbEJeSKxVbdacDTBAA\%3d

[38] A.J.S. Montes, H.A.B. Castro and J.A.H. Riveros, "How to motivate students to work in the laboratory: A new approach for an electrical machines laboratory," IEEE Trans. on Education, vol. 53, no. 3, pp. 490-496, Aug. 2010.

[39] Omicron CMC356: Universal relay test set and commissioning tool (available on June 18, 2015)

https://www.omicron.at/fileadmin/user_upload/pdf/literature/CMC-356-BrochureENU.pdf

[40] Ponovo Universal test system L336i, (available on June 18, 2015) http://www.relaytest.com/userfiles/file/Catalogs/L336i_Brochure.pdf

[41] Adobe Acrobat Commenting Tool, (available on June 18, 2015) http://tv.adobe.com/watch/acrobat-tips-and-tricks/using-familiar-commentingtools/

[42] Curtin's online system for gathering and reporting student feedback on their learning experiences. (available on June 18, 2015) https://evaluate.curtin.edu.au

[43] Vacancies for Engineers, Engineers Australia Fact Sheet, Engineers Australia (available on June 18, 2015)

https://www.engineersaustralia.org.au/sites/default/files/shado/Resources/vacanci es_for_engineers_jan_2015_update_dec_stats.pdf

[44] Engineering Labor Market Analysis, Engineers Australia (available on June 18, 2015)

https://www.engineersaustralia.org.au/about-us/engineering-labour-marketanalysis 